九州大学学術情報リポジトリ

Kyushu University Institutional Repository

\title{
Cytochrome c Peroxidase from Phanerochaete chrysosporium
}

Nonaka, Da i suke

Laboratory of Bioresources Chemistry, Division of Biomaterial Sciences, Department of Forest and Forest Products Sciences, Graduate School of Bioresource and Bioenvironmental Sciences, Kyushu University

Wari ishi, Hiroyuki

https://doi.org/10.5109/4633

出版情報：九州大学大学院農学研究院紀要. 50 (1)，pp.151-164，2005-02-01. Faculty of Agriculture, Kyushu University

バージョン :

権利関係 : 


\title{
Cytochrome c Peroxidase from Phanerochaete chrysosporium
}

\author{
Daisuke NONAKA ${ }^{1}$ and Hiroyuki WARIISHI*
}

\author{
Laboratory of Bioresources Chemistry, Division of Biomaterial Science, Department of \\ Forest and Forest Products Sciences, Faculty of Agriculture, \\ Kyushu University, Fukuoka 812-8581, Japan \\ (Received November 5, 2004 and accepted November 15, 2004)
}

\begin{abstract}
Cytochrome $c$ peroxidase from the white-rot basidiomycete Phanerochate chrysosporium ( $\mathrm{PcCcP}$ ) was investigated. A phylogenic analysis of $\mathrm{PcCcP}$ amino acid sequence showed that $\mathrm{PcCcP}$ was closely related to cytochrome $c$ peroxidase from Saccharomyces cerevisiae (yeastCcP) and pea cytosolic ascorbate peroxidase (APX). Recombinant PcCcP was obtained by expression in Eshcherichia coil and a heme incorporation into the apoenzymes. Spectral charactersitics indicated that the heme iron of $\mathrm{PcCcP}$ was mainly 5-coordinated high spin species. The absorption spectrum of PcCcP compound I and rapid-scan spectra of compound I formation strongly suggested that $\mathrm{PcCcP}$ compound I was ferryoxy heme iron and protein cation radical, as observed in yeastCcP. Although several typical peroxidase substrates, small organic or inorganic compounds, were not oxidized by $\mathrm{PcCcP}$, ferrocytochrome $c$ was effectively oxidized. Both $\mathrm{PcCcP}$ and yeastCcP shared catalytic features. A homology modeling of $\mathrm{PcCcP}$ and cytochrome $c$ from $P$. chrysosporium $(\mathrm{PcCc}$ ) strongly suggested the interaction between PcCcP and PcCc.
\end{abstract}

\section{INTRODUCTION}

Lignin is a heterogeneous, phenylpropanoid polymer that constitutes $20-30 \%$ of woody plant cell walls (Sarkanen et al., 1970). White-rot basidiomycetous fungi are primarily responsible for initiating the depolymerization of lignin, which is a key step in the earth's carbon cycle (Crawford, 1980; Gold et al., 1989; Kirk and Farrell, 1987; Tien, 1987). The best-studied lignin-degrading fungus, Phanerochaete chrysosporium, secretes two types of extracellular heme peroxidases, lignin peroxidase (LiP) and manganese peroxidase $(\mathrm{MnP})$, which are the major extracellular components of its lignin degradative system (Gold et al., 1989; and Kirk and Farrell, 1987). Both enzymes were known to catalyze the first step of degradation of lignin polymers using hydrogen peroxide (Gold et al., 1989).

Since the whole genomic sequence of $P$. chrysosprium was made open to public (Martinez et al., 2004), the survey for all heme peroxidase genes in the $P$. chrysosporium genome via BLAST homology search was performed. Several $\mathrm{LiP}$ and $\mathrm{MnP}$ gene fragments as well as a gene fragments showing a high similarity to cytochrome $c$ peroxidase from Saccharomyces cerevisiae (yeastCcP) were found.

YeastCcP (ferrocytochrome $c$ /hydrogen peroxide oxidoreductase; EC 1.11.1.5) occurs naturally in the mitochondrial intermembrane space and catalyzes the $\mathrm{H}_{2} \mathrm{O}_{2}$-dependent

\footnotetext{
1 Laboratory of Bioresources Chemistry, Division of Biomaterial Sciences, Department of Forest and Forest Products Sciences, Graduate School of Bioresource and Bioenvironmental Sciences, Kyushu Univérsity

* Corresponding author (E-mail: hirowari@agr.kyushu-u:ac.jp)
} 
one-electron oxidation of ferrous cytochrome $c\left(\mathrm{Cc}^{2+}\right)$ to ferric cytochrome $c$ ( $\left(\mathrm{Cc}^{3+}\right)$ (Bosshad et al., 1990). Most striking difference between yeastCcP and common peroxidases are found in their compound I structures (Sivaraja et al., 1989; Erman and Yonetani, 1975). Generally, a peroxidase catalytic cycle was described as below.

$$
\begin{aligned}
& \text { Resting state }\left(\mathrm{Fe}^{3+}\right)+\mathrm{H}_{2} \mathrm{O}_{2} \rightarrow \text { Compound I }\left(\mathrm{Fe}^{4+}=\mathrm{O}, \mathrm{R} \bullet\right) \\
& \text { Compound I }\left(\mathrm{Fe}^{4+}=\mathrm{O}, \mathrm{R} \bullet\right)+\mathrm{SH} \rightarrow \text { Compound II }\left(\mathrm{Fe}^{4+}=\mathrm{O}\right)+\mathrm{S} \bullet \\
& \text { Compound II }\left(\mathrm{Fe}^{4+}=\mathrm{O}\right)+\mathrm{SH} \rightarrow \text { Resting state }\left(\mathrm{Fe}^{3+}\right)+\mathrm{S} \bullet+\mathrm{H}_{2} \mathrm{O}
\end{aligned}
$$

In the first step of the peroxidase catalytic cycle, the resting state enzyme, which has ferric heme iron, is oxidized by hydrogen peroxide to form compound I, where $\mathrm{R}$ is an organic moiety. Then, compound I is reduced back to the resting enzyme via compound II by subtracting two electrons from reducing substrates (SH). Usually, peroxidase compound I was comprised of ferryloxy heme iron and porphyrin $\pi$ cation radical. In yeastCcP compound I, ferryloxy heme iron is also formed as observed in most other peroxidases; however, cation radical is located at Trp191 rather than porphyrin $\pi$ cation radical (Sivearaja et al., 1989). In addition, interaction and electron transfer between yeastCcP and cytochrome $c$ have been well studied as a model system for two macromolecules (Bosshard et al., 1990; Erman and Vitello, 2002).

Consequently, yeastCcP has been paid much attention in respect to those unique functions and catalytic mechanisms. Since the forefront research techniques have been applied to yeastCcP to reveal its characters, yeastCcP became the paradigm for all other peroxidases.

In the present study, a structural characterization of cytochrome $c$ peroxidase (PcCcP) gene from $P$. chrysosporium as well as its cloning and heterologous expression in Escherichia coli is reported. The recombinant protein exhibited the $\mathrm{H}_{2} \mathrm{O}_{2}$-dependent activity of ferrous cytochrome $c$ oxidation.

\section{MATERIALS AND METHODS}

\section{Chemicals}

$\mathrm{H}_{2} \mathrm{O}_{2}$ (30\% solution) and 2, 6-dimethoxyphenol (DMP) were obtained from Wako Pure Chemicals Co. Ltd. $\mathrm{H}_{2} \mathrm{O}_{2}$ stock solution $(10 \mathrm{mM})$ was prepared daily and the concentration was checked as previously described (Cotton and Dunford, 1973). DMP was recrystallized from ethanol/hexane. All other chemicals were of reagent grade. Deionized water was obtained from Milli Q system (Millipore).

\section{Cloning of PcCcP gene and construction of the expression vector}

$P$. chrysosporium cDNA was synthesized from totalRNA, which was isolated from 4-day-old stationary culture of $P$. chrysosporium, with M-MLV reverse transcriptase (Takara) and oligo dT primers. Following primers were constructed according to BLAST results using yeastCcP amino acid sequence against $P$. chrysosporium genome sequence; CcP-S-51 (AGGGCTGCGGGCCTCCGTAA, 20 mer), CcP-A-1448 (CGTATATGAGCATCTATGACGCCTCGCA, $28 \mathrm{mer}$ ). PcCcP fragment was synthesized by polymerase chain reaction, using $\mathrm{CcP}-\mathrm{S}-51$ and $\mathrm{CcP}-\mathrm{A}-1448$, and cloned into pGEM-T Easy Vector 
(Promega). Signal peptide prediction was achieved using SOSUI (http://sosui.proteome. bio.tuat.ac.jp/sosuiframe0E.html) and SignalP (http://www.cbs.dtu. $\mathrm{dk} /$ services/SignalP-2.0/) programs. For expression of PcCcP polypeptides in E. coli, a mature PcCcP sequence with 74 base pairs truncated fragment was amplified using following primers; PcCcP_exp_forw (CCCAAGCTTCATATGAGCGAAGCCGCGAAATCTG; 34 mer) and PcCcP_exp_reve (CGGGATCCCTACGACGACTTCGCCTCCT; 28 mer). The resulting fragment was digested with Nde I and Bam HI and cloned into pET-12a (+) (Novagen). Resulting vector was named pET-tPcCcP.

\section{Expression of PcCcP in Escherichia coli}

E. coli BL21(DE3)pLysS (Novagen) transformed with pET-tPcCcP was grown in LB-broth supplemented with $100 \mu \mathrm{g} / \mathrm{ml}$ ampicillin and $34 \mu \mathrm{g} / \mathrm{ml}$ chloramphenicol at $37^{\circ} \mathrm{C}$. An initial small-scale expression was conducted in $2 \mathrm{ml}$ culture at $30^{\circ} \mathrm{C}$ or $37^{\circ} \mathrm{C}$. At the time of O.D.6im showing $\sim 0.6,0.4 \mathrm{mM}$ isopropyl-thio- $\beta$-D-galactopyranoside (IPTG), $0.5 \mathrm{mM} 5$-aminolevulinic acid (ALA), and $0.2 \mathrm{mM}$ ferrous sulfate was added to induce the expression of active PcCcP. Incubation time was prolonged for another 6 to $21 \mathrm{~h}$. The cells were harvested by centrifugation at $9,000 \mathrm{rpm}$ for $3 \mathrm{~min}$ and directly used for activity assay.

\section{Purification of PcCcP}

For a larger-scale preparation of $\mathrm{PcCcP}$, the cells were grown in a 3-L jar-fermenter without the addition of ALA and ferrous sulfate; thus, apo-PcCcP was obtained. After collection of the cells by centrifugation, they were resuspended in $50 \mathrm{mM}$ Tris- $\mathrm{Cl}, \mathrm{pH} 8.0$ containing $2 \mathrm{mM}$ EDTA and stored at $-80^{\circ} \mathrm{C}$. Then, $2 \mathrm{mg} / \mathrm{ml}$ lysozyme, $1 \mathrm{mM}$ phenylmethylsulfonylfluoride, $0.1 \%$ Triton X-100, 1 U DNase, and $1 \mathrm{U}$ RNase were added and incubated for $1 \mathrm{~h}$ at $30^{\circ} \mathrm{C}$ with gentle stirring. The incorporation of heme into apo-protein was achieved as reported for the yeastCcP expression system (Teske et al., 2000). A concentrated hemin solution (final concentration of $\sim 500 \mu \mathrm{M}$ ) was added into the lysed cell suspention and incubated at $4^{\circ} \mathrm{C}$ for at least $30 \mathrm{~min}$ with gentle stirring. Then, the solution was acidified at pH 5.0 with $1 \mathrm{M}$ acetic acid, and incubated on ice for $30 \mathrm{~min}$. During this procedure, a large amount of contaminated proteins and excess heme were precipitated. After centrifugation, the solution was diluted by 20 times with deionized water and $\mathrm{pH}$ of the solution was adjusted to $\mathrm{pH}$ 6.0. The enzyme solution was loaded onto DEAE Sepharose Fast Flow (Amersham Biosciences) equilibrated with $10 \mathrm{mM}$ phosphate, $\mathrm{pH}$ 6.0. PcCcP was eluted with $500 \mathrm{mM}$ phosphate, $\mathrm{pH}$ 6.0. The fractions showing $\mathrm{CcP}$ activity were combined and dialysed against $10 \mathrm{mM}$ phosphate, $\mathrm{pH} 6.0$, for $16 \mathrm{~h}$. The dialyzed sample was concentrated and final purification was achieved using Mono-Q (Amersham Biosciences) with a multilinear gradient with $10 \mathrm{mM}$ phosphate, $\mathrm{pH} 6.0$ and $1 \mathrm{M}$ phophate, $\mathrm{pH} 6.0$ at a flow rate of $1 \mathrm{ml} / \mathrm{min}$. The purified enzyme was dialyzed against deionized water overnight and stored at $4^{\circ} \mathrm{C}$.

\section{Cytochrome $c$ preparations}

Yeast iso-1 cytochrome $c$ were purchased from Aldrich and used without further purification. Ferrous cytochrome $c\left(\mathrm{Cc}^{2+}\right)$ was prepared as previously described (Johjima et al., 2002; Wariishi et al., 1994). Concentration of $\mathrm{Cc}^{2+}$ was determined spectropho- 
tometrically using a molar extinction coefficient at $550 \mathrm{~nm}$ of $27.6 \mathrm{mM}^{-1} \mathrm{~cm}^{-1}$ (Yonetani, 1965).

\section{Spectroscopic Analysis}

Electronic absorption spectra were recorded using a Perkin Elmer Lambda 19 spectrophotometer at $25^{\circ} \mathrm{C}$.

\section{Steady-state kinetic analysis}

Initial rates of substrate oxidation were spectrophotometrically measured at $25^{\circ} \mathrm{C}$. All steady-state kinetic experiments were performed in $20 \mathrm{mM}$ phosphate, $\mathrm{pH} 6.0$. The rate of DMP oxidation (quinone dimmer formation) was determined from the increase in absorbance at $469 \mathrm{~nm}$ using $\Delta \varepsilon$ of $49.6 \mathrm{mM}^{-1} \mathrm{~cm}^{-1}$ (Wariishi et al., 1992). The rate of ferrocyanide oxidation (ferricyanide formation) was determined using $\Delta \varepsilon_{4 \geq 0}$ of $1.02 \mathrm{mM}^{-1} \mathrm{~cm}^{-1}$ (Schellenberg and Hellerman., 1958). The rate of ABTS oxidation (ABTS cation radical formation) was determined using $\Delta \varepsilon_{415}$ of $36.0 \mathrm{mM}^{-1} \mathrm{~cm}^{-1}$ (Smith et al., 1990). All reactions were initiated by adding $0.1 \mathrm{mM} \mathrm{H}_{2} \mathrm{O}_{2}$. Steady-state kinetic prameters were calculated from the Lineweaver-Burk prot. The reaction of $\mathrm{PcCcP}$ with $\mathrm{Cc}^{2+}$ and L-ascorbate was determined at $550 \mathrm{~nm}$ and $290 \mathrm{~nm}$, respectively.

\section{Transient-state kinetic analysis}

Kinetic measurements were conducted using a Photal RA 401S Rapid Reaction Analyzer (Otsuka Electronics Co. Ltd.) equipped with a 1-cm observation cell at $25.0 \pm$ $0.1^{\circ} \mathrm{C}$. The formation rate of $\mathrm{PcCcP}$ compound I was determined at $417 \mathrm{~nm}$, the maximum absorption wavelength of compound I. One reservoir contained native PcCcP (ca. $2 \mu \mathrm{M}$ ) and the other reservoir contained $\mathrm{H}_{2} \mathrm{O}_{2}(5-15 \mu \mathrm{M})$ in $40 \mathrm{mM}$ phosphate, $\mathrm{pH}$ 6.0. The pseudo-first order rate constants were determined by a non-linear least-squares fit to exponential traces.

\section{Homology modeling of PcCcP}

A homology model of the PcCcP tertiary structure was constructed with MOE program (Chemical Computing Group Inc.), according to manufacturer's instructions and as previously reported (Rupasinghe et al., 2003), using yeastCcP structure (PDB code: 2CYP) as a template structure. The truncated PcCcP amino acid sequence with a deletion of 82 amino acids in N-terminal and 10 amino acids in C-terminal sequences from the original sequence was applied to homology model programs, since those sequences showed no homology to the mature yeastCcP sequence. After construction of the initial homology model, further energy minimization was performed using the CHARMm22 force field (MacKerell et al., 1998) within the MOE distribution until the final energy gradient became $<0.01 \mathrm{kcal} / \mathrm{mol}$. A. A distance-dependent dielectric constant was used in the calculations with a cutoff between 6.5 and $7 \AA$.

\section{RESULTS AND DISCUSSION}

\section{PcCcP amino acid sequence}

The fragment showed a high similarity to the yeastCcP sequence was amplified using 
primers designed from the $P$. chrysosporium genome sequence (Martinez et al., 2004). The resulting fragment was cloned and sequenced. A phylogenic analysis of the deduced $\mathrm{PcCcP}$ amino acid sequence and several typical peroxidases clearly showed that $\mathrm{PcCcP}$ was classified into class I plant peroxidase superfamily, which was comprised of intracellular peroxidases from plant and bacteria, and that the most closely related to yeastCcP (43\%) and pea cytosolic ascorbate peroxidase (APX) (41\%) (Fig. 1).

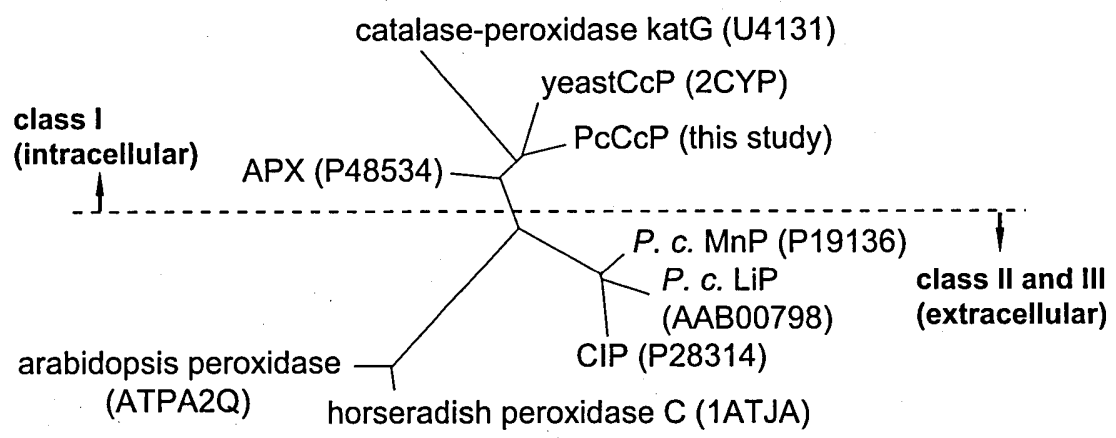

Fig. 1. Phylogenic tree of PcCcP and typical peroxidases. Phylogenic tree was calculated and visualized by Tree View program using Neighbor-Joining method (Saitou et al., 1987). NCBI accession numbers of each protein were shown in parenthesis.

A further detailed analysis of the $\mathrm{PcCcP}$ amino acid sequence was performed via ClustalW alignment using yeastCcP and APX (Fig. 2). Essential amino acids for peroxidative mechanism, e.g. the proximal histidine, distal histidine, and distal arginine, were also conserved in $\mathrm{PcCcP}$. One of the most interesting characteristics of yeastCcP was its compound I structure. YeastCcP compound I has been known to possess ferryloxy heme iron and Trp191 cation radical rather than ferryloxy heme iron and porphyrin $\pi$ cation radical found in plant and fungal peroxidases (Sivaraja et al., 1989). Sequential analysis revealed that the existence of Trp residue (Trp275) in $\mathrm{PcCcP}$ at the corresponding position of Trp191 in yeastCcP. Furthermore, yeastCcP is known to oxidize $\mathrm{Cc}^{2+}$, its physiological substrate, on the protein surface (Bosshard et al., 1990). Becasuse of basic character of $\mathrm{Cc}^{2+}$, yeastCcP was known to possess acidic amino acid residues involved in $\mathrm{Cc}^{2+}$ binding on its protein surface (Pelletier and Kraut, 1992 and Guo et al., 2004). Sequential alignment analysis revealed that $\mathrm{PcCcP}$ has such acidic residues, which might construct a $\mathrm{Cc}^{3+}$ binding site on the surface of PcCcP. Interestingly, amino acid resiudes forming a proposed electron transfer pathway $\mathrm{W}^{191} \mathrm{G}^{192} \mathrm{~A}^{193} \mathrm{~A}^{194}$ in yeastCcP (Pelletier and Kraut, 1992), was replaced in PcCcP as $\mathrm{W}^{2 \pi 5} \mathrm{~T}^{2 \pi 6} \mathrm{~F}^{2 \pi r} \mathrm{~S}^{2 \pi 8}$.

A PSORT analysis of $\mathrm{PcCcP}$ amino acid sequence suggested that $\mathrm{PcCcP}$ might localize in mitochondria and first 65 amino acids from initial methionine might be a signal peptide. Furthermore, SOSUI program suggested that PcCcP has a transmembrane region (Fig. 2, underlined) in its $\mathrm{N}$-terminal. PcCcP might be localized in mitochondria as shown for yeastCcP. 


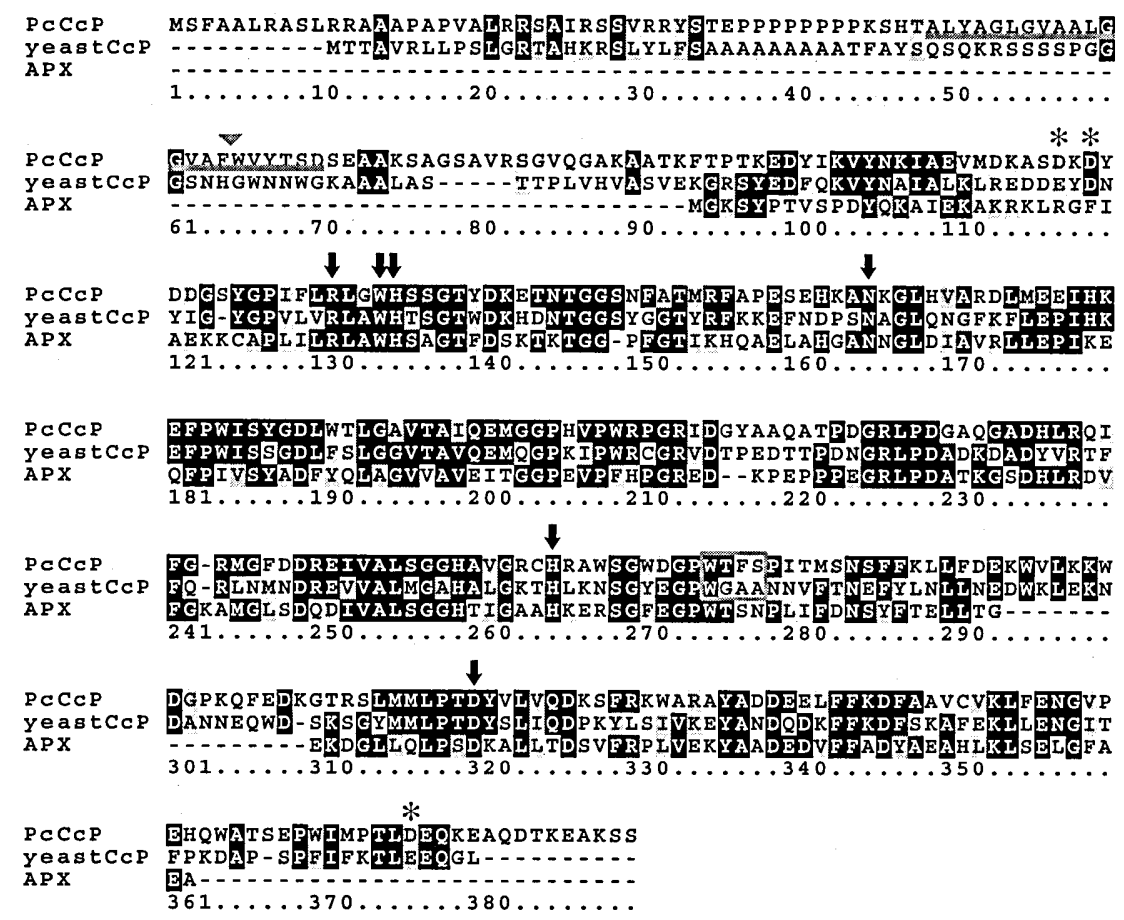

Fig. 2. ClustalW alignment of amino acid sequences between $\mathrm{PcCcP}$, yeastCcP and APX. The alignment was generated by ClustalW and visualized by boxshade program. Arrows indicate conserved amino acids, which are essential for peroxidative activity. Amino acids involved in electron transfer between yeastCcP and $\mathrm{Cc}^{2+}$ were enclosed in a gray box. Acidic amino acids, involved in binding of basic $\mathrm{Cc}^{2+}$ at the enzyme surface of yeastCcP, are indicated in asterisks. Underlined residues at $\mathrm{N}-$ terminal are membrane-bound region predicted by SOSUI program and a triangle indicates the signal peptides cleavage site which was predicted by PSORT program.

\section{Expression of PcCcP in E. coli}

According to PSORT and SOSUI results, the first 71 amino acids were truncated and designed to have N-terminal sequence of MSEAA-, then cloned into pET-12a(+). E. coli strain BL21(DE3)pLysS transformed with pET-tPcCcP was grown in LB culture containing ALA and $\mathrm{FeSO}_{4}$. Six hours after induction, cells were collected and the $\mathrm{H}_{2} \mathrm{O}_{2}$-dependent $\mathrm{Cc}^{2+}$ oxidation activity of the lysed cells was determined (Fig. 3). Only when $\mathrm{Cc}^{2+}$ was incubated with the induced cells and hydrogen peroxide, $\mathrm{Cc}^{2+}$ oxidation activity was observed. The highest activity was observed after a $14-\mathrm{h}$ incubation at $30^{\circ} \mathrm{C}$ (data not shown). Fig. 4 illustrated SDS-PAGE analysis of expression of PcCcP in E. coli strain BL21(DE3)pLysS. PcCcP polypeptides were expressed only in IPTG induced cells. The predicted molecular weight of $33.6 \mathrm{kDa}$ was confirmed for expressed PcCcP. Incubation at $37^{\circ} \mathrm{C}$ resulted in accumulation of insoluble form of PcCcP polypeptides as inclusion bodies. 


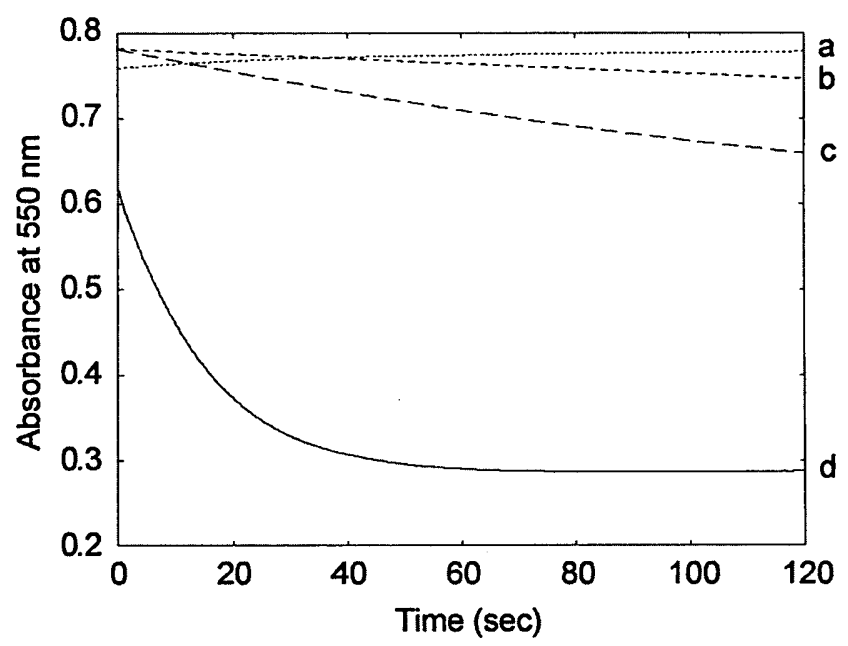

Fig. 3. Ferrocytochrome $c$ oxidation by PcCcP expressed in $E$. coli. $34 \mu \mathrm{M} \mathrm{Cc}^{2+}$ was incubated with IPTG-induced $E$. coli cells only (trace a), $0.1 \mathrm{mM} \mathrm{H}_{2} \mathrm{O}_{2}$ only (trace b), non-induced $E$. coli cells and $0.1 \mathrm{mM} \mathrm{H}_{2} \mathrm{O}_{2}$ (trace c), and induced $E$. coli cells and $0.1 \mathrm{mM}$ $\mathrm{H}_{2} \mathrm{O}_{2}$ (trace d) in $20 \mathrm{mM}$ phosphate, $\mathrm{pH} 7.2$.

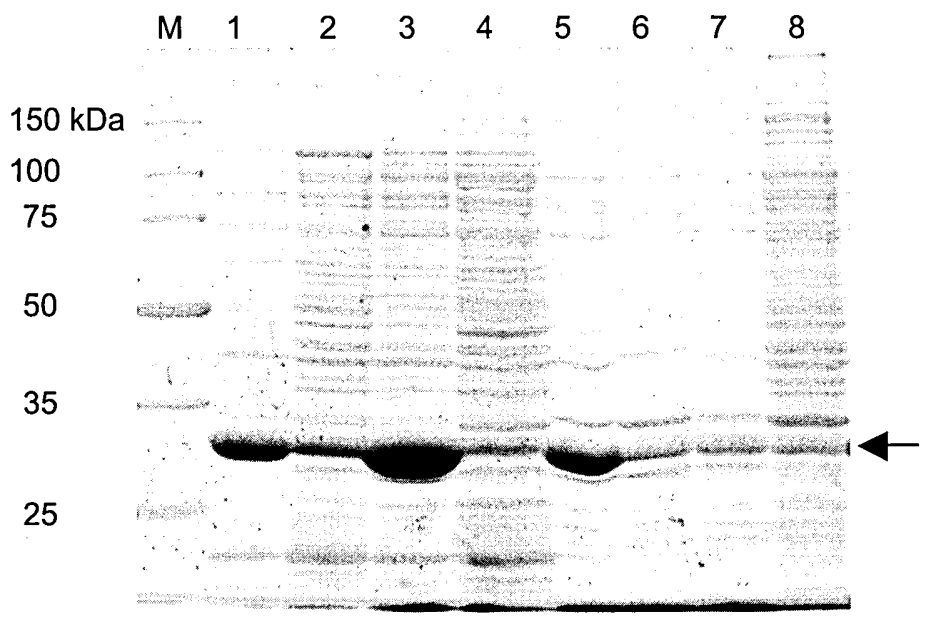

Fig. 4. SDS-PAGE analysis of $\mathrm{PcCcP}$ protein expressed in E. coli. Expression of $\mathrm{PcCcP}$ were induced (lanes $1-3$ and $5-7$ ) by the addition of $0.4 \mathrm{mM}$ IPTG or not induced (lanes 4 and 8 ). $E$. coli cells were incubated at $37^{\circ} \mathrm{C}$ for 6 hours (lanes 1 and 5) and at $30^{\circ} \mathrm{C}$ for 6 hours (lanes $3,4,7$ and 8 ) or 21 hours (lanes 2 and 6 ). After lysed with lysozyme treatment, proteins were fractionated by centrifugation into soluble fraction (lanes 1-4) and insoluble fraction (lanes 5-8). Bands derived from $\mathrm{PcCcP}$ are marked with arrows. Protein samples were prepared with SDS-PAGE sample buffer, which contains $3 \mathrm{M}$ urea, $2 \%$ SDS, $2.5 \%$ 2-ME, $75 \mathrm{mM}$ DTT and $10 \%$ glycerol. 


\section{Preparation of recombinant $\mathrm{PcCcP}$}

In large-scale incubation, $\mathrm{PcCcP}$ protein was recovered as apo-form. An active enzyme was obtained via in vitro incorporation of the heme into the apoprotein. Active $\mathrm{PcCcP}$ was effectively purified using two chromatograms, DEAE Sepharose Fast Flow and Mono-Q. Elution profile of $\mathrm{PcCcP}$ from Mono-Q was shown in Fig. 5. Final yield of the recombinant $\mathrm{PcCcP}$ was about $70 \mathrm{mg} / \mathrm{L}$ culture medium.

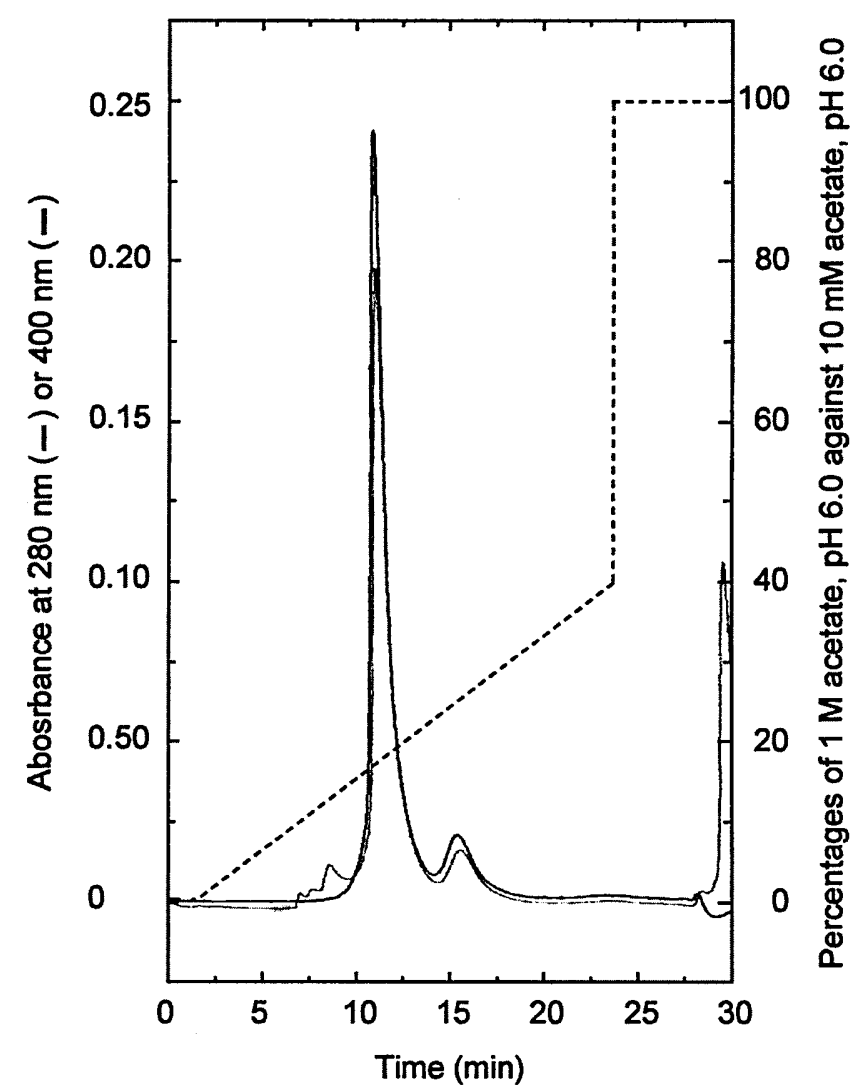

Fig. 5. Elution profile of PcCcP from Mono-Q column. Black and gray lines indicates absorbance at 280 and $400 \mathrm{~nm}$, respectively (on the left $\mathrm{y}$-axis). Dashed line shows percentages of $1 \mathrm{M}$ acetate, $\mathrm{pH} 6.0$ in $10 \mathrm{mM}$ acetate, $\mathrm{pH} 6.0$ (on the right $\mathrm{y}$-axis). $\mathrm{PcCcP}$ was eluted at $11.3 \mathrm{~min}$.

\section{Electronic absorption spectra of PcCcP}

Purified PcCcP exhibited RZ value of 0.82. Extinction coefficient at $405 \mathrm{~nm}$ for the resting enzyme was determined to be $118.9 \mathrm{mM}^{-1} \mathrm{~cm}^{-1}$ using pyridine-hemochromogen method (Paul et al., 1953). Fig. 6 shows an electronic absorption spectrum of PcCcP in 


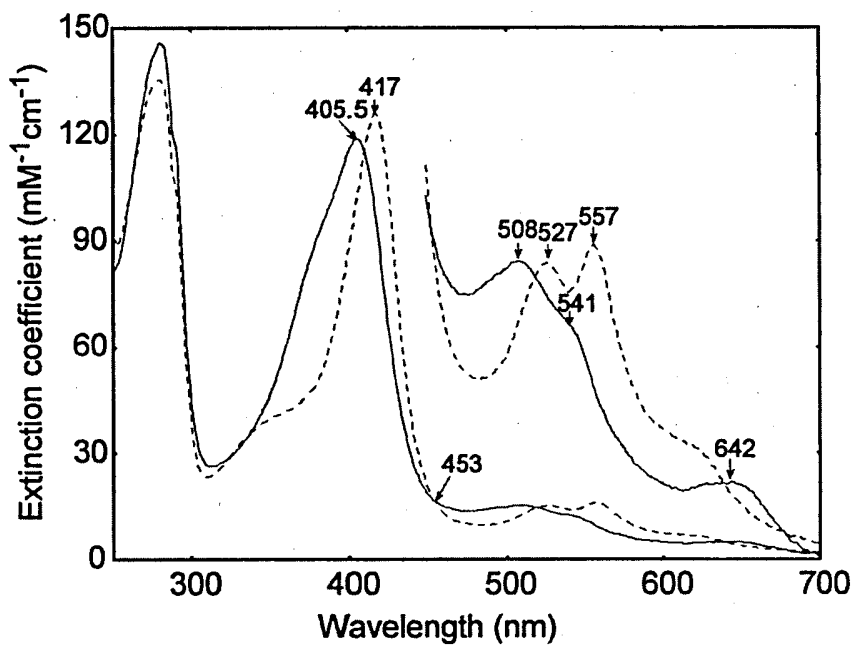

Fig. 6. Electronic absorption spectrum of resting state (solid line) and compound I (broken line). $3 \mu \mathrm{M}$ PcCcP was used. Compound I was generated by adding the equimolar hydrogen peroxide to the resting enzyme.
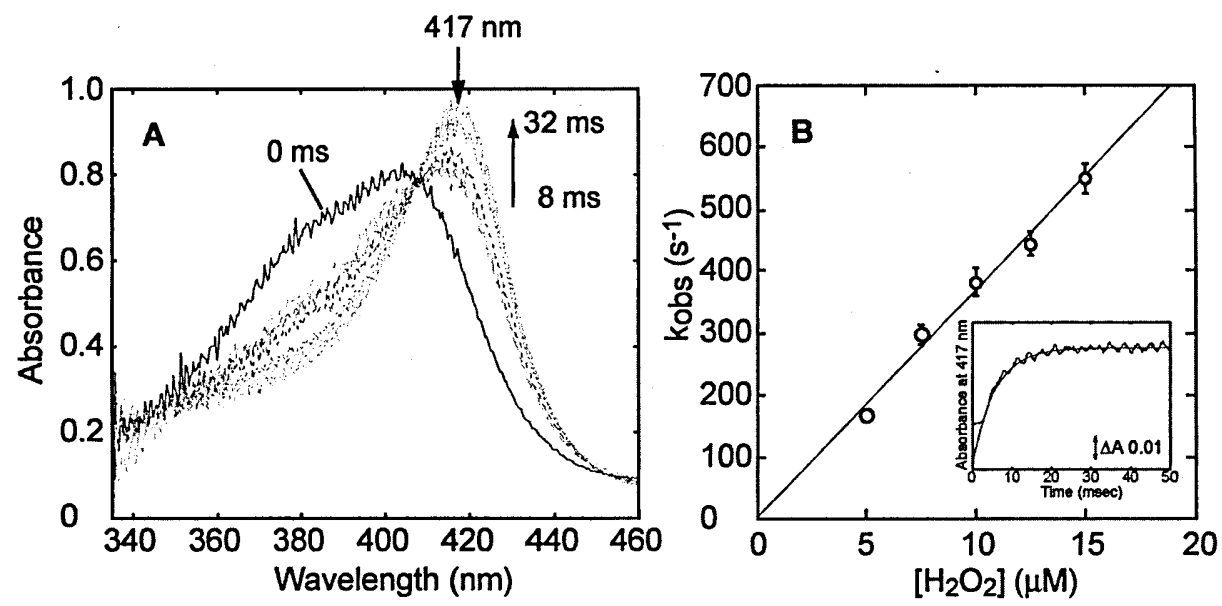

Fig. 7. Transient-state kinetic analysis of $\mathrm{PcCcP}$ compound I formation. A: Rapid-scan spectra of compound I formation. B: Compound I formation rate of $\mathrm{PcCcP}$. Inset shows typical kinetic trace at $417 \mathrm{~nm}$. 
$20 \mathrm{mM}$ phosphate, $\mathrm{pH} 6.0$. The absorption spectrum of resting enzyme showed the Soret maximum at $405.5 \mathrm{~nm}$ with a shoulder at $\sim 380 \mathrm{~nm}$, and visible peaks at $508 \mathrm{~nm}, 541 \mathrm{~nm}$ and $642 \mathrm{~nm}$, strongly suggesting that the heme iron of recombinant PcCcP was five-coordinated high spin. High numbers of aromatic amino acids (19 phenylalanines, 13 tryptophanes, and 12 tyrosines) in PcCcP is the reason for a low number of RZ value and could also be one of the reasons that easier formation of inclusion bodies, compared to yeastCcP.

$\mathrm{PcCcP}$ compound I was generated by adding the equimolar of hydrogen peroxide, resulting in the Soret maximum at $417 \mathrm{~nm}$. The absorption spectrum of $\mathrm{PcCcP}$ compound I resembled that of yeastCcP compound I which has the Soret maximum at $419 \mathrm{~nm}$. Thus, $\mathrm{PcCcP}$ compound I might contain the ferryloxy heme iron and an amino acid cation radical, probably at Trp275.

YeastCcP compound II was reported to be the mixture of ferryloxy iron and Trp cation radical; thus, its absorption spectrum is not distinguishable (Coulson et al., 1971). $\mathrm{PcCcP}$ compund II was prepared by adding equimolar ferrocyanide to PcCcP compound I. The resulting spectrum of $\mathrm{PcCcP}$ was very similar to that of the resting state (data not shown), suggesting PcCcP compound II also possessed yeastCcP-like protein based cation radical, probably with less characteristics of ferryloxy feature of the heme.

\section{Stopped-flow analysis of PcCcP compound I formation}

Further characterization of $\mathrm{PcCcP}$ compound I was conducted using a stopped-flow rapid-scan analysis. Fig. 5A showed rapid-scan spectra of the reaction between the resting state enzyme and $\mathrm{H}_{2} \mathrm{O}_{2}$ from $8 \mathrm{~ms}$ to $32 \mathrm{~ms}$ after mixing. The isosbestic points at 345 , 407 , and $455 \mathrm{~nm}$ clearly indicated that the reaction proceeded in a single step. Then, the $\mathrm{PcCcP}$ compound I formation rate was determined by following the change in absorbance at $417 \mathrm{~nm}$. The values of $k_{\text {obs }}$ were obtained using exponential fit to the kinetic traces (Fig. $5 \mathrm{~B}$ inset). The first-order rate constant for PcCcP formation $\left(\mathrm{k}_{1}\right)$ was evaluated to be $3.6 \times 10^{7} \mathrm{M}^{-1} \mathrm{~s}^{-1}$ by plotting $\mathrm{k}_{\text {obs }}$ values against $\mathrm{H}_{2} \mathrm{O}_{2}$ concentrations (Fig. 5B). The intersection of the regression line of the plots at the origin indicated that the reaction between $\mathrm{PcCcP}$ and $\mathrm{H}_{2} \mathrm{O}_{2}$ was irreversible.

\section{Cytochrome $c$ oxidation by PcCcP}

Since $\mathrm{PcCcP}$ amino acid sequence showed a high similarity against both yeastCcP and APX, as shown in Fig. 2, one-electron oxidation ability of purified PcCcP against cytochrome $c$ and L-ascorbate, which were physiological substrates for yeastCcP and APX, respectively, were investigated. In the presence of $\mathrm{H}_{2} \mathrm{O}_{2}, \mathrm{PcCcP}$ effectively catalyzed an one-electron oxidation of $\mathrm{Cc}^{2+}$ (Fig. 8). On the other hand, no significant change was observed in the reaction between PcCcP and L-ascorbate (Fig. 8). These observations strongly suggested that $\mathrm{L}$-ascorbate is not a substrate of $\mathrm{PcCcP}$ but $\mathrm{Cc}^{2+}$ is.

\section{Substrate specificity of PcCcP}

Steady-state kinetic parameters for reactions between $\mathrm{PcCcP}$ and a series of typical peroxidase substrates were determined (Table 1). PcCcP showed low activities against DMP (phenolic substrate), ABTS (typical anionic substrate), ferrocyanide (inorganic substrate). Furthermore, veratryl alcohol and manganese (II), which are physiological sub- 


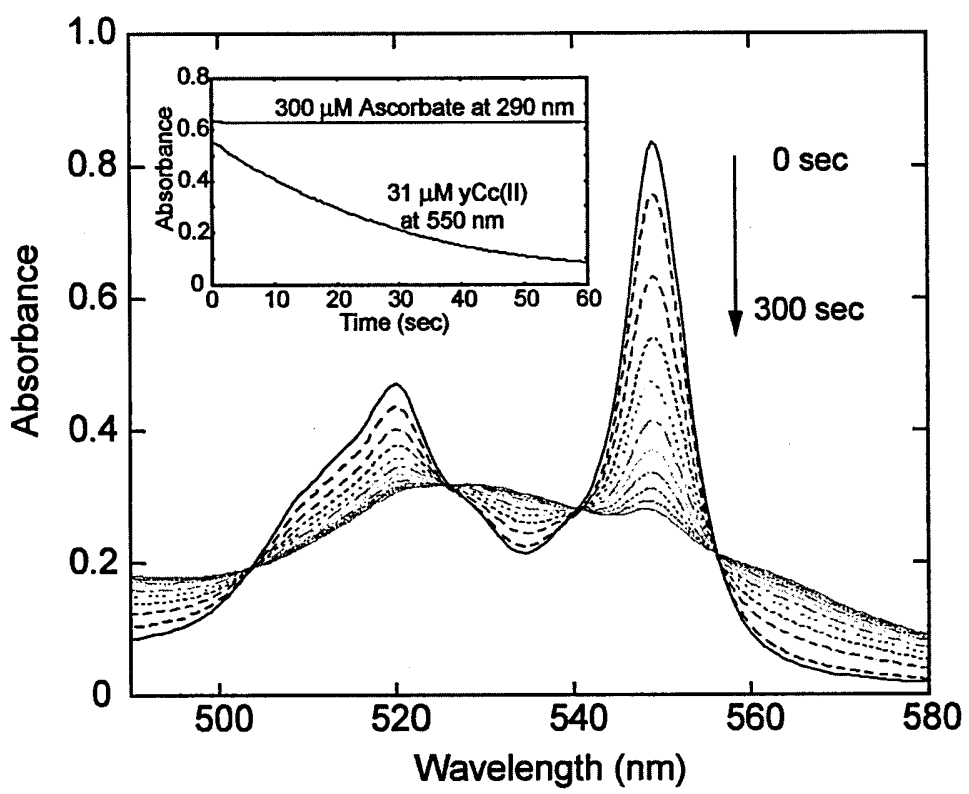

Fig. 8. Time course of the reaction between $\mathrm{PcCcP}$ and $\mathrm{Cc}^{2+} .31 \mu \mathrm{M} \mathrm{Cc}^{2+}$ was incubated with $0.85 \mathrm{nM} \mathrm{PcCcP}$ and $50 \mu \mathrm{M} \mathrm{H}_{2} \mathrm{O}_{2}$ in $20 \mathrm{mM}$ phosphate, $\mathrm{pH}$ 6.0. Each spectrum was measured every 3 minutes after addition of $\mathrm{H}_{2} \mathrm{O}_{2}$. Inset shows kinetic traces of reactions between $\mathrm{PcCcP}$ and $\mathrm{Cc}^{2+}$ or L-ascorbate.

Table 1. Steady-state kinetic parameters of various substrates oxidation catalyzed by PcCcP.

\begin{tabular}{cccc}
\hline & $\begin{array}{c}\mathrm{Km} \\
(\mathrm{mM})\end{array}$ & $\begin{array}{c}\mathrm{k}_{\text {cat }} \\
(\mathrm{mmol} / \mathrm{min} / \mathrm{mmol})\end{array}$ & $\begin{array}{c}\mathrm{k}_{\mathrm{car}} / \mathrm{Km} \\
\left(\mathrm{mM}^{-1} \mathrm{~min}^{-1}\right)\end{array}$ \\
\hline DMP & 17 & 56 & 3.3 \\
ABTS & 0.41 & 390 & 951 \\
Ferrocyanide & 68 & 213800 & 3144 \\
\hline
\end{tabular}

strates for $\mathrm{LiP}$ and $\mathrm{MnP}$ were not reacted with $\mathrm{PcCcP}$.

\section{Homology modeling of PcCcP}

A homology model of $\mathrm{PcCcP}$ was constructed with MOE program using yeastCcP crystal structure (2CYP) as a template structure (Fig. 9). Obtained final model showed a root mean square value of $1 \AA$ against yeastCcP crystal structure (PDB code; 2CYP) in respect to $\mathrm{C} \alpha$ carbon, suggesting that the $\mathrm{PcCcP}$ structural model was correctly constructed. Pelletier et al. (1992) reported that acidic residues on the surface of yeastCcP were involved in binding to basic $\mathrm{Cc}^{2+}$, based on the co-crystal structure of yeastCcP and cytochrome $c$. Acidic amino acids were also existed on the surface of the PcCcP model structure and the number of those residues were much higher than those of yeastCcP, 
A

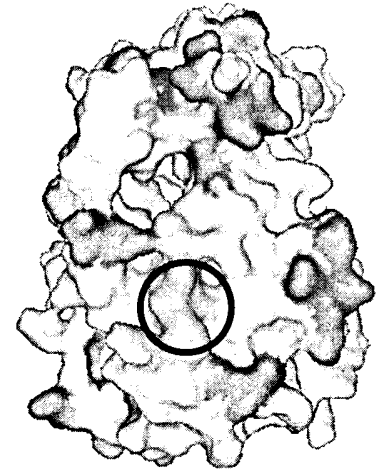

PcCcP

B

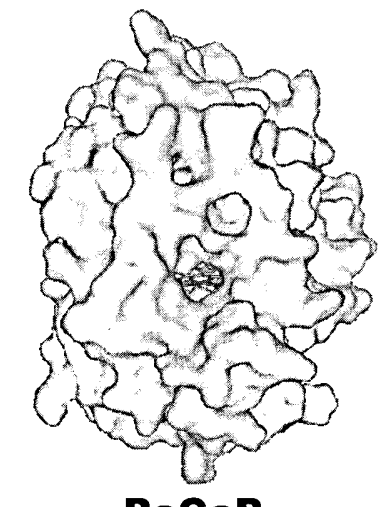

PcCcP

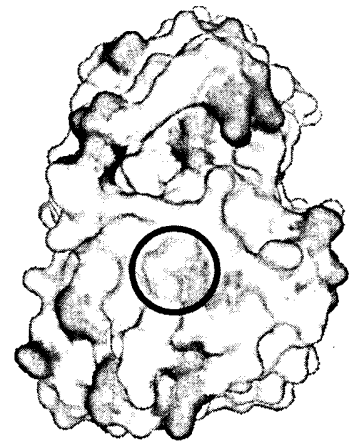

yeastCcP

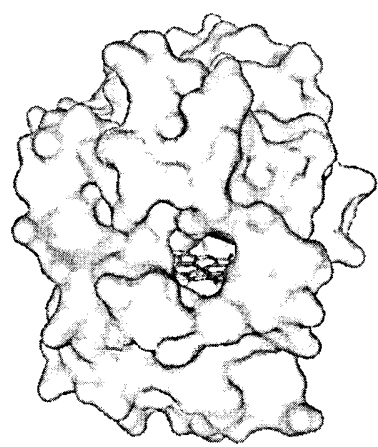

APX

Fig. 9. Homology model of PcCcP. Panel A: Acidic amino acids on the protein surface of PcCcP and yeastCcP. Acidic amino acids (glutamate or aspartate) are indicated in dark color. The proposed electron transfer site in yeastCcP (Pelltier and Kraut, 1992) or the corresponding residues in $\mathrm{PcCcP}$ were enclosed in circles. Panel B: Comparison of heme pocket architecture of $\mathrm{PcCcP}$ and APX. Heme was emphasized in gray.

indicating surface of $\mathrm{PcCcP}$ was much more acidic than that of yeastCcP (Fig. 9A). The model structure for cytochrome $c$ of $P$. chrysosporium $(\mathrm{PcCc})$, which was annotated from $P$. chrysosporium genome sequence by a BLAST search using cytochrome $c$ sequence of $S$. cerevisiae was constructed. The surface of $\mathrm{PcCc}$ was basic with calculated pI of 9.6 , which was comparable to pI of 11 for yeast iso-1 cytochrome $c$. Because of lower $\mathrm{pI}$ for $\mathrm{PcCc}$, strongly acidic surface characteristics might be required for PcCcP.

APX shows no activity against $\mathrm{Cc}^{2+}$ despite of its sequence similarity against yeastCcP. The most preferred substrate of APX is L-ascorbate, its physiological substrate. Crystal structure of ascorbate peroxidase-ascorbate complex (Sharp et al., 2003) showed that cationic amino acid residues, Lys 30 and Arg 172, were mostly contributed to the binding 
of L-ascorbate, an anionic substrate. These two cationic amino acids were substituted to Gly and Asn in yeastCcP and Gly and Trp in PcCcP, respectively (Fig. 2). These structural characteristics are in good accordance with the observation that PcCcP exhibited the oxidation activity towards $\mathrm{Cc}^{2+}$ but not to L-ascorbate (Fig. 8).

$\mathrm{PcCcP}$ showed only a weak activity towards typical peroxidase substrates (Table 1). Furthermore, PcCcP showed no activity against manganese (II) or veratryl alcohol, which were physiological substrates for MnP and LiP, respectively (Gold et al., 1989). These observations clearly indicated that substrate specificity of $\mathrm{PcCcP}$ was strictly restricted to $\mathrm{Cc}^{2+}$ and, furthermore, $\mathrm{PcCcP}$ seemed not to be involved in neither L-ascorbate nor lignin metabolism. Substrate specificity of $\mathrm{PcCcP}$ was further evidenced by the homology model of PcCcP. Fig. 9B showed comparison of heme pocket entrance between PcCcP and APX. Narrower heme pocket of PcCcP, compared to that of APX, might prevent the interaction of reducing substrates with the heme of $\mathrm{PcCcP}$.

A physiological function of yeastCcP was not completely understood. Especially, a physiological meaning of $\mathrm{Cc}^{2+}$ oxidation by yeastCcP is still unclear. However, the induction of yeastCcP mRNA by oxidative stress was reported (Kwon et al., 2003) and this enzyme might be involved in anitioxidative system in mitochondria. Proteomic analysis surveying the conditions to optimize $\mathrm{PcCcP}$ production is now underway. Our recent proteomic data indicated the up-regulation of $\mathrm{PcCcP}$ production under $100 \%$ oxygen atmosphere (data not shown). PcCcP may be involved in antioxidative system.

\section{CONCLUSION}

$P$. chrysospoium genome sequence data enabled us to survey various enzymes. This is the first time to exhibit that cytochrome $c$ peroxidase was active and functional in basidiomycetes. Recombinant PcCcP was successfully obtained via the $E$. coli expression system. The structural characteristics were suggested to be very similar to yeastCcP. Spectral, kinetic, and sequential analyses of $\mathrm{PcCcP}$ revealed that recombinant $\mathrm{PcCcP}$ catalyzes the $\mathrm{H}_{2} \mathrm{O}_{2}$-dependent $\mathrm{Cc}^{2+}$ oxidation via a typical peroxidase catalytic cycle.

\section{REFERENCES}

Bosshard, H. R., H. Anni and T. Yonetani 1990 Yeast cytochrome $c$ peroxidase. In "Peroxidases in Chemistry and Biology" (Everse, J., Everse, K. E., and Grisham, M. B., Eds.), Vol. II, CRC Press, Boca Raton, FL, pp. 51-84

Cotton, M. L. and H. B. Dunford 1973 Studies on horseradish peroxidase XI: On the nature of compounds I and II as determined from the kinetics of the oxidation of ferrocyanide. Can. J. Chem., 51: $582-587$

Coulson, A. F. W., J. E. Erman and T. Yonetani 1971 Studies on cytochrome $c$ peroxidase. XVII. Stoichiometry and mechanism of the reaction of compound ES with donors. J. Biol. Chem., 246: 917-924

Crawford, R. L. 1980 Lignin Biodegradation and Transformation, Wiey, New York

Erman, J. E. and L. B. Vitello 2002 Yeast cytochrome $c$ peroxidase: mechanistic studies via protein engineering. Biochim. Biophys. Acta., 1597: 193-220

Erman, J. E. and T. Yonetani 1975 A kinetic study of the endogenous reduction of the oxidized sites in the primary cytochrome $c$ peroxidase-hydrogen peroxide compound. Biochim. Biophys. Acta., 393: 350-357

Gold, M. H., H. Wariishi and K. Valli 1989 Whitaker, J. R. and P. Sonnet (Eds.), Proceedings of the ACS 
Symposium Series 389 on Biocatalysis in Agricultural Biotechnology, American Chemical Society, Washington, DC, pp. 127-140

Guo, M., B. Bhaskar, H. Li, T. P. Barrows and T. L. Poulos 2004 Crystal structure and characterization of a cytochrome $c$ peroxidase-cytochrome $c$ site-specific cross-link. Proc. Natl. Acad. Sci. U. S. A., 101: $5940-5945$

Johjima, T., H. Wariishi and H. Tanaka 2002 Veratryl alcohol binding sites of lignin peroxidase from Phanerochaete chrysosporium. J. Mol. Cat. B: Enzym., 17: 49-57

Kirk, T. K. and R. L. Farrell 1987 Enzymatic "combustion": the microbial degradation of lignin. Annu. Rev. Microbiol., 41: 465-505

Kwon, M., S. Chong, S. Han and K. Kim 2003 Oxidative stresses elevate the expression of cytochrome $c$ peroxidase in Saccharomyces cerevisiae. Biochim. Biophys. Acta., 1623: 1-5

MacKerell, A. D., Jr., D. Bashford, R. L. Bellott, R. L. Dunbrack, Jr., J. D. Evanseck, M. J. Field, S. Fischer, J. Gao, H. Guo, S. Ha, D. Joseph-McCarthy, L. Kuchnir, K. Kuczera, F. T. K. Lau, C. Mattos, S. Michnick, T. Ngo, D. T. Nguyen, B. Prodhom, W. E. Reiher, III, B. Roux, M. Schlenkrich, J. C. Smith, R. Stote, J. Straub, M. Watanabe, J. Wiorkiewicz-Kuczera, D. Yin and M. Karplus 1998 All-Atom Empirical Potential for Molecular Modeling and Dynamics Studies of Proteins. J. Phys. Chem. B., 102: $3586-3616$

Martinez, D., L. F. Larrondo, N. Putnam, M. D. Gelpke, K. Huang, J. Chapman, K. G. Helfenbein, P. Ramaiya, J. C. Detter, F. Larimer, P. M. Coutinho, B. Henrissat, R. Berka, D. Cullen and D. Rokhsar 2004 Genome sequence of the lignocellulose degrading fungus Phanerochaete chrysosporium strain RP78. Nat. Biotechnol., 22: 695-700

Paul, K. G., H. Theorell and $\AA$. Åkeson 1953 The molar light absorption of pyridine ferroprotoporphyrin (pyridine haemochromogen). Acta Chem. Scand., 7: 1284-1287

Pelletier, H. and J. Kraut 1992 Crystal Structure of a Complex Between Electron Transfer Partners, Cytochrome $c$ Peroxidase and Cytochrome $c$. Science, 258: 1748-1755

Rupasinghe, S., J. Baudry and M. A. Schuler 2003 Common active site architecture and binding strategy of four phenylpropanoid P450s from Arabidopsis thaliana as revealed by molecular modeling. Protein Eng., 16: 721-731

Saitou, N. and M. Nei 1987 The neighbor-joining method: a new method for reconstructing phylogenetic trees. Mol. Biol. Evol., 4: 406-425

Sarkanen, K. V. and C. H. Ludwig 1970 Lignins: Ocurrence, Formation, Structure and Reactions, Wliey, New York

Schellenberg, K. A. and L. Hellerman 1958 Oxidation of reduced diphosphopyridine nucleotide. J. Biol. Chem., 231: 547-556

Sharp, K. H., M. Mewies, P. C. Moody and E. L. Raven 2003 Crystal structure of the ascorbate peroxidase-ascorbate complex. Nat. Struct. Biol., 4: 303-307

Sivaraja, M., D. B. Goodin, M. Smith and B. M. Hoffman 1989 Identification by ENDOR of Trp191 as the free-radical site in cytochrome $c$ peroxidase compound ES. Science, 245: 738-740

Smith, A. T., N. Santama, S. Dacey, M. Edwards, R. C. Bray, R. N. Thorneley and J. F. Burke 1990 Expression of a synthetic gene for horseradish peroxidase $\mathrm{C}$ in Escherichia coli and folding and activation of the recombinant enzyme with $\mathrm{Ca}^{2+}$ and heme. J. Biol. Chem., 265: 13335-13343

Teske, J. G., M. I. Savenkova, J. M. Mauro, J. E. Erman and J. D. Satterlee 2000 Yeast cytochrome $c$ peroxidase expression in Escherichia coli and rapid isolation of various highly pure holoenzymes. Protein Expr. Purif., 19: 139-147

Tien, M. 1987 Properties of ligninase from Phanerochaete chrysosporium and their possible applications. CRC Crit. Rev. Microbiol., 15: 141-168

Wariishi, H., K. Valli and M. H. Gold 1992 Manganese(II) oxidation by manganese peroxidase from the basidiomycete Phanerochaete chrysosporium. Kinetic mechanism and role of chelators. J. Biol. Chem., 267: 23688-23695

Wariishi, H., D. Sheng and M. H. Gold 1994 Oxidation of ferrocytochrome $c$ by lignin peroxidase Biochemistry, 33: 5545-5552

Yonetani, T. 1965 Studies on cytochrome $c$ peroxidase. II. Stoichiometry between enzyme, $\mathrm{H}_{2} \mathrm{O}_{2}$, and ferrocytochrome $c$ and enzymic determination of extinction coefficients of cytochrome $c$. J. Biol. Chem., 240: 4509-4514

Yonetai, T. 1976 The Enzymes, 3rd ed., P. D. Boyer, ed., Academic, New York, Vol. 13, pp. 345-361 